\title{
Characteristics of Dry Cold Air Intrusion in a Typical Strong Storm Process
}

\author{
Yanjing Tang1, Bo Liao', Tao Wei ${ }^{2}$ \\ ${ }^{1}$ Guizhou Meteorological Service Center, Guiyang, China \\ ${ }^{2}$ Guizhou Meteorological Observatory, Guiyang, China \\ Email:370128885@qq.com
}

How to cite this paper: Tang, Y. J., Liao, B., \& Wei, T. (2019). Characteristics of Dry Cold Air Intrusion in a Typical Strong Storm Process. Journal of Geoscience and Environment Protection, 7, 223-238. https://doi.org/10.4236/gep.2019.74015

Received: September 20, 2018

Accepted: April 25, 2019

Published: April 28, 2019

Copyright () 2019 by author(s) and Scientific Research Publishing Inc. This work is licensed under the Creative Commons Attribution International License (CC BY 4.0).

http://creativecommons.org/licenses/by/4.0/

\begin{abstract}
Taking a typical strong storm in Guizhou on April 5, 2017 for example, the diagnosis analysis used the water vapor cloud and the initial field of EC thin grid, including physical quantity, surface and upper air meteorological observation, as well as radar observation data. For the environment parameter analysis, small CAPE value tended to underestimate storm intensity on potential forecast stage, strong vertical wind shear revealed the strong dry cold air was the important intensity factors of the storm. The water vapor cloud map can be used to monitor the most important features, the dry zone, the wet zone and the boundary between them. When dry intrusion is found, it can be used as one of the bases for the development of heavy rain. Dry cold air intrusion on high-level was traced by water vapor images. And in this process, the analyses revealed the role of dry cold air's influence on intensity of the storm.
\end{abstract}

\section{Keywords}

Strong Storm, Dry Cold Air, Storm Intensity

\section{Introduction}

Hail is a relatively perennial severe weather phenomenon in the plateau. Large hail is a hail that is more than $2 \mathrm{~cm}$ in diameter when landing on the ground. The occurrence of large hail is often accompanied by strong winds. It is often called a storm disaster and often causes huge production and life loss. In the Yunnan-Guizhou Plateau, spring is a season of hail and windy, and storm disasters have always been the focus of the weather forecasting service and research in Guizhou Province.

At present, in recent years, many studies have been done on the hail weather caused by thunderstorms on the ground, from meteorological features, vertical 
wind shear, stratification stability, numerical simulation and radar product characteristics (Yu et al., 2006; Lei, 1986; Liu et al., 2011; Wang et al., 2009; Yao et al., 2015; Zheng et al., 2014; Li et al., 2011). The fruitful results: such as Yu Xiaoding (Yu et al., 2006) and so on through a large number of case studies, summed up a series of weather radar business characteristics and indicators in hail weather; Lei Yushun (Lei, 1986) used energy methods and unstable parameters in strong rain forecasting. A lot of research work has been done on the analysis and forecasting of convective weather. Liu Yizhen (Liu et al., 2011) discovered some convective and energy parameters with physical significance through systematic research on local strong convection. In response to the storm weather in Guizhou Province, relevant scholars have carried out some research on mesoscale weather classification and radar echo characteristics (Wan et al., 2017; Chen et al., 2017; Zhou et al., 2012).

The research on windy weather is mainly based on radar data analysis and weather analysis, and the water vapor cloud image is rarely used for analysis. The space-time high resolution of water vapor cloud map can make up for the spatial limitation of radar data, and play an important role in the monitoring and tracking of medium and high altitude weather systems, especially dry and cold air. In view of the intrusion of dry and cold air in the middle and upper levels, the related research mainly draws qualitative research conclusions from the instability of the layer caused by dry and cold air intrusion (Chen et al., 2017; Qian et al., 2007; Xu et al., 2010), and there is less tracking and characteristic analysis of dry and cold air. A large number of studies have shown that the most significant weather activity of dry and cold air-dry intrusion is not only beneficial to the occurrence and development of weather scale systems, but also to the development of sub-weather system instability (Browning, 1997), and even the development of medium cyclones and tornadoes. The strong weather system generates a favorable promotion (Leslie, 1998; Yu \& Yao, 2003). The role of dry and cold air intrusion in small and medium-scale windy weather needs further study.

This article takes a typical strong convective weather in Guizhou Province on April 5, 2017 as an example. Although the dry and cold air intrusion intensity of this popular weather cannot meet the dry intrusion standard, it can still be identified and analyzed with reference to the definition and characteristics of dry intrusion (Browning, 1997; Yu \& Yao, 2003; Browing \& Golding, 1995). In the analysis method, the mesoscale weather analysis is used to combine the water vapor cloud map with the initial field of the EC fine grid pattern, including the physical quantity field, as well as meteorological observations and radar observation data on the ground and high altitude for diagnostic analysis. The initial field of the EC fine mesh mode is used as the live field replacement analysis. The mature mode is used to assimilate the sounding reality with a variety of data. It has considerable reliability and can be used for small and medium-scale strong convective weather analysis. To maximize the advantages of its high resolution, this paper focuses on the use of water vapor images to track the characteristics of 
mid- and high-level dry and cold air intrusion in this typical strong storm process, in order to reveal the key factors affecting storm intensity in weather systems that are conducive to strong convection.

\section{Weather Conditions}

From 16:00 to 6:00 on April 5, 2017, there were mixed strong convective weather such as short-term heavy rainfall, hail, thunderstorm and strong wind in the central and eastern part of Guizhou Province (Figure 1). Among them, the southern cities and counties of Guiyang City and Puding and Yuqing counties A total of 17 townships have hail, the largest hail diameter is $20 \mathrm{~mm}$ in Zhoujiazhai Village, Huaxi, Guiyang City, and $27 \mathrm{~m} / \mathrm{s}$ thunderstorm gale in Qingzhen City; heavy rain is concentrated in Guiyang, central Guizhou Province, a total of 41 stations.

The important disaster-stricken weather of this strong convective weather is windy, with long duration, high intensity, and concentrated regional characteristics (Figure 2): the hail begins at 18:09 on the 5th (Xindian Town, Qingzhen), followed by the hail cloud from west to east. Sweeping the southern part of Guiyang City, around 21:10, in the urban area of Guiyang, the small hail is less than $5 \mathrm{~mm}$, but the density of hail is very large, and the dense hail is about $2-8$ $\mathrm{cm}$ thick on the ground until it melts the next day (Figure 3). At 21:52, a $20 \mathrm{~mm}$ diameter hail was produced in Zhoujiazhai, Huaxi, and then the intensity of the hail was weakened. After the small hail of $5 \mathrm{~mm}$ in diameter appeared in Yuqing around $8: 30$ on the 6 th, the hail process ended.

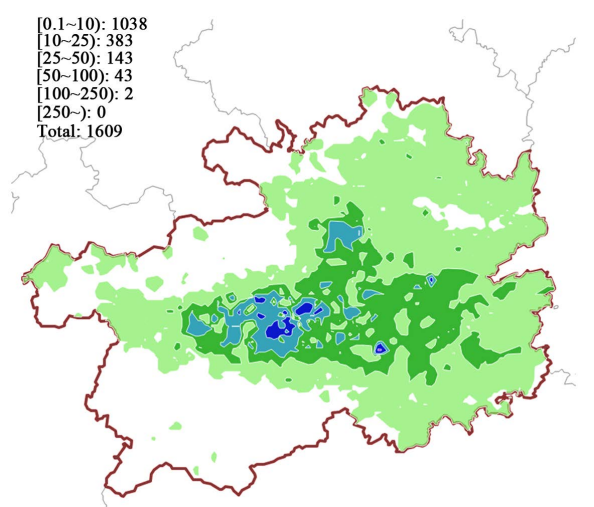

Figure 1. Accumulated rainfall from 16:00, April 5, 2017 to 08:00, April 6, 2017.
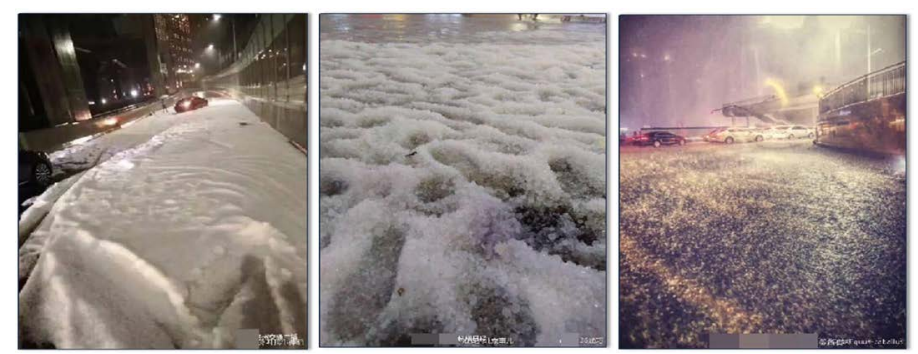

Figure 2. Hail drop of Guiyang on April 5, 2017 (from network). 


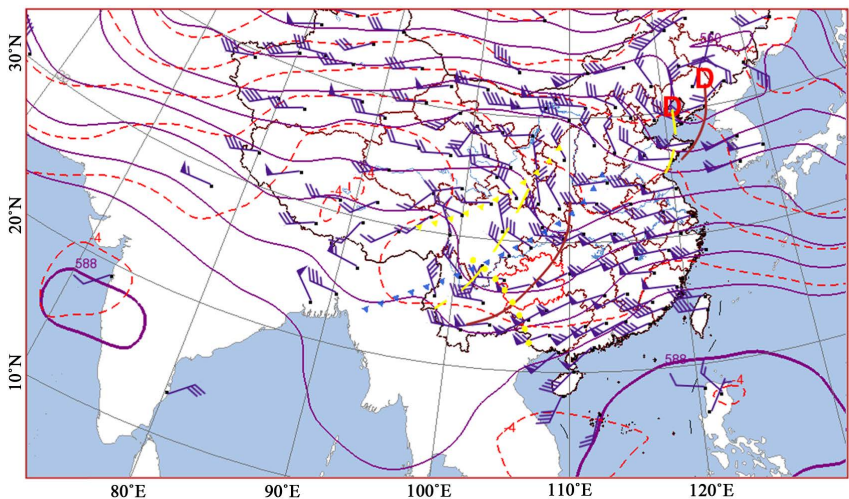

(a)

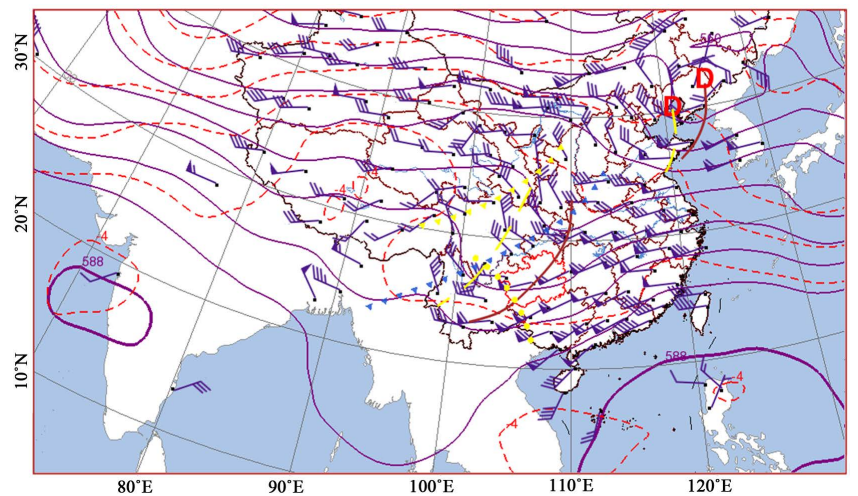

(b)

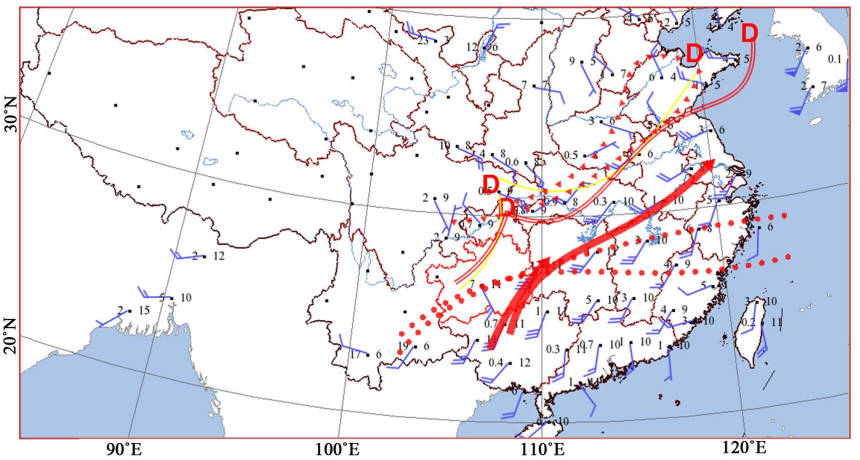

(c)

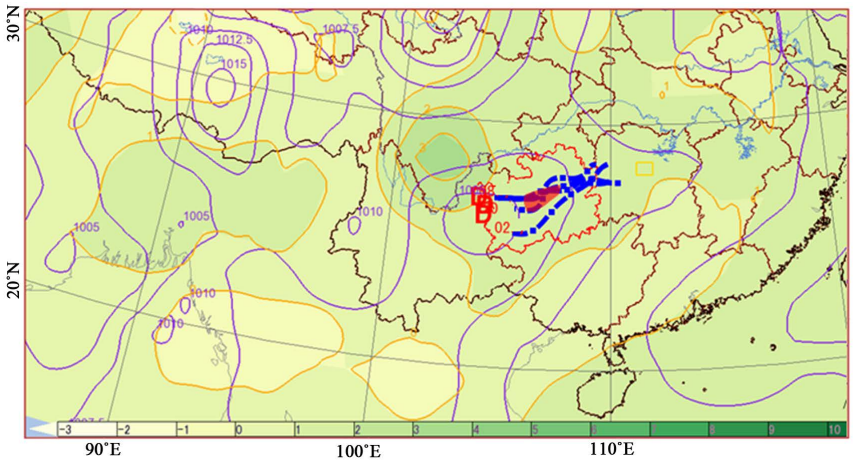

(d)

Figure 3. Weather system evolution on April 5, 2017, 8:00 to 20:00. (a) $500 \mathrm{hPa}$; (b) 700 $\mathrm{hPa}$; (c) $850 \mathrm{hPa}$; (d) surface weather systems analysis and forecasted hail zone (red area). 
In the process, the forecaster made an accurate drop determination in the short-term weather forecast for the day, but the wind strength was underestimated. Especially in the Guiyang urban area of the provincial capital, a large number of hail is rare. Four districts (cities) in Guiyang suffered from wind and flood disasters, causing casualties and economic losses. A large number of small hailstones in Guiyang, or artificial destruction operations on the same day, caused a sharp change in cloud microphysical processes, but like the largest 20 $\mathrm{mm}$ hail (Huaxi Zhoujiazhai), it is a product of strong convective weather. The following will mainly discuss the effects of storm intensity on weather systems and factors in this strong convective weather.

\section{Weather Characteristics Analysis}

\subsection{Situation Analysis}

On April 5, 2017, $200 \mathrm{hPa}$ Guizhou Province was on the right side of the high-altitude jet inlet area, which is conducive to the development of the ascending movement; $500 \mathrm{hPa}$ province is in front of the high-altitude trough, accompanied by lagging temperature trough; $700 \mathrm{hPa}$ and $850 \mathrm{hPa}$ low-vortex shear system from The north of Chongqing is slowly moving eastward and southward. The territory of Guizhou is controlled by the southerly airflow. The low-level jet stream is maintained in the southern part of Guizhou. The temperature trough with the east shearing and the temperature ridge accompanying the southwest rapids are obvious. The cold and warm air meets over Guizhou. At 20 o'clock, the temperature gradient is obviously increased; most of the central and western Guizhou are under the control of thermal low pressure, and the low-pressure center is less moving. The east-west convergence line of the central part of Guizhou Province is stable, and the west section of the 17-hour width line gradually hems. At 02 o'clock, it turned to northeast-southwest.

On the infrared cloud map, the hail cloud system develops rapidly, the boundary is clear, and there are obvious MCS features. The occurrence is located in the northwest of Guizhou Province. The development is located on the north side of the ground width line and the south side of the $850 \mathrm{hPa}$ shear line. After the $500 \mathrm{hPa}$ high-altitude trough, the cold air before the cold trough, the activity of the cold air in the middle and the upper part of the $200 \mathrm{hPa}$ jet stream entrance area Conducive to the development of convection.

\subsection{Analysis of Environmental Parameters and Stratification Status}

In this process, the main hail area is near Guiyang, and Guiyang's hail time is around 21 o'clock. Therefore, Guiyang sounding is very representative and can reveal the vertical vertical stratification characteristics of such typical strong convective weather before and during hail. The production of strong winds is mainly restricted by three environmental parameters: 1) convective effective potential energy (CAPE); 2) vertical wind shear; and 3) $0^{\circ} \mathrm{C}$ layer height ( $\mathrm{Wu} \& \mathrm{Yu}$, 2009). 
At 8:00 on May, Guiyang sounding was a typical upper dry and wet structure (Figure 4). The CAPE value was $148.5 \mathrm{~J} / \mathrm{kg}$ (Table 1). After the temperature was corrected at 14 o'clock in the afternoon, it was only $380 \mathrm{~J} / \mathrm{kg}$. The high altitude is strong southwesterly wind (700 - $400 \mathrm{hPa}$ average wind speed $21 \mathrm{~m} / \mathrm{s}$ ), vertical wind shear reaches medium intensity; $0^{\circ} \mathrm{C}$ layer height, $-20^{\circ} \mathrm{C}$ layer height are favorable to the favorable height of hail in Guizhou. The sounding also reveals that the dry and cold features of the middle and upper floors are obvious, coupled with the high wind speed, which corresponds to dry and cold air and strong dry air. At 20 o'clock on the 5th, the storm has formed and is located in the northwest of Guiyang. The CAPE and vertical wind shear are obviously strengthened, the wet layer is obviously thickened, and many storm intensity indicators are directed toward the strong storm increase. It shows that after the development of hot and low pressure in the daytime, the transportation of warm and humid airflow will tend to be unstable, and the potential of updraft and convective development will increase. At the same time, it is noted that the relative humidity of the $850 \mathrm{hPa}$ near-surface layer is significantly reduced, the specific humidity is also reduced to $10 \mathrm{~g} / \mathrm{kg}$, and the wet layer is raised above the near-surface layer.

Judging from the configuration of the three environmental productions, the probability of occurrence of hail and strong wind in this process is very large, and it is a configuration with a small CAPE value and a strong vertical wind shear. Studies have shown that vertical wind shear has the greatest influence on convective storm tissue and characteristics in deep wet convection with specified

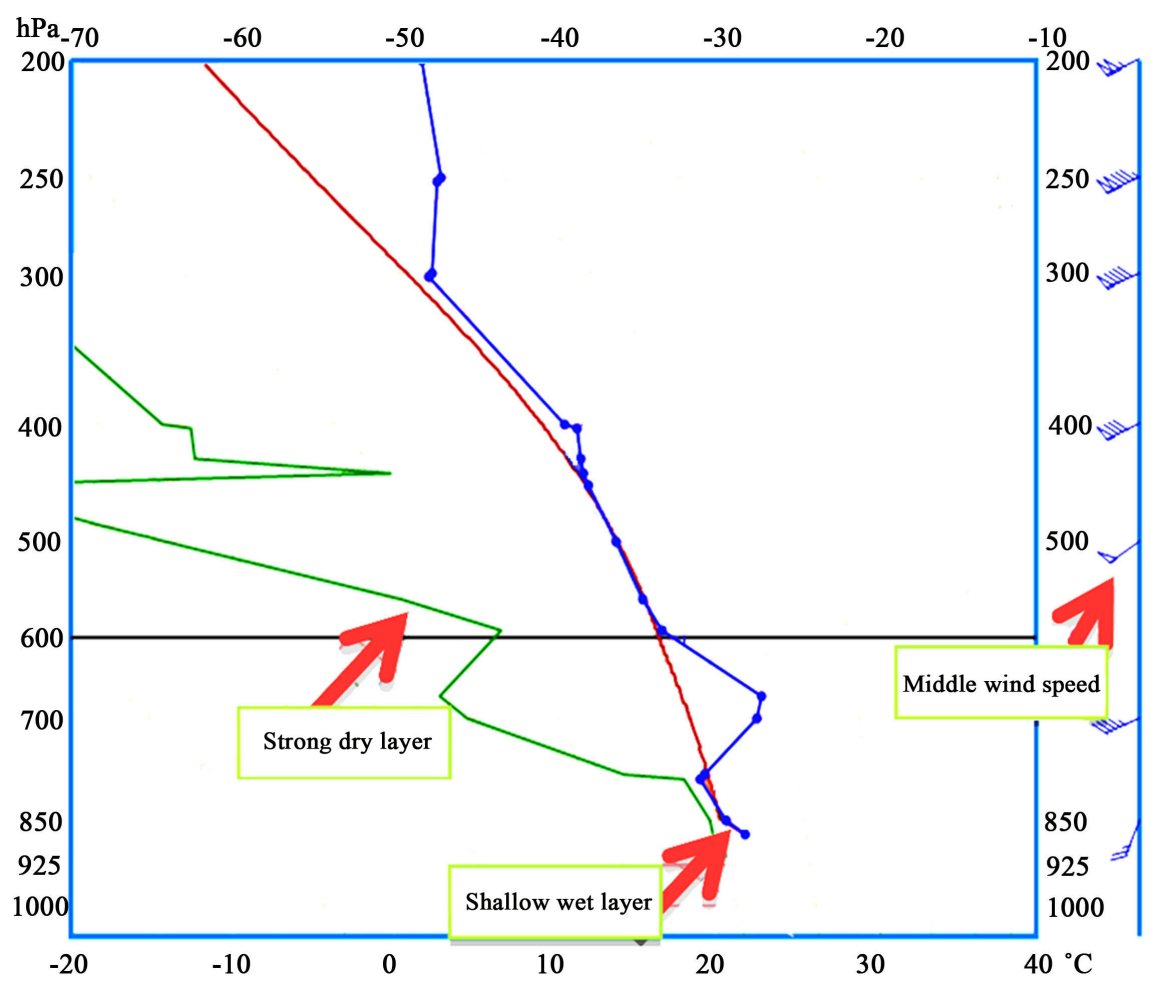

Figure 4. T-logp diagram from Guiyang sounding at 8:0, April 5, 2017. 
Table 1. Environmental parameters at 8:00 and 20:00, April 5, 2017.

\begin{tabular}{ccc}
\hline Index name and unit & 08:00, April 5, 2017 & 20 o'clock on April 5, 2017 \\
\hline Zero layer height $\mathrm{m}$ & 4495.8 & 4405 \\
-20 degree layer height & 7591.2 & 7450 \\
Wet convection effective energy CAPEJ/kg & 148.5 & 549 \\
$0-6 \mathrm{~km}$ vertical wind shear m/s & 15.38 & 24.22 \\
Normalized vertical wind shear m/s & 1.25 & 1.96 \\
\hline
\end{tabular}

humidity, instability and uplift (Wu \& Yu, 2009; Yu et al., 2005; Chen et al., 2007; Johns \& Doswell, 1992), and its contribution to the ascending airflow intensity in the storm body can be Reach or even exceed the effective energy of convection (Johns \& Doswell, 1992). Under the action of strong vertical wind shear, strong dry cold air can enter the sinking airflow formed in the storm, forming a strong wind on the ground: dry cold air brings strong evaporation of water vapor, evaporation negative buoyancy is favorable for strong downwinding; storm body The inflow of dry cold air on the rear side enhances the mid-level convergence, which in turn enhances the updraft and also enhances the downdraft. In addition, the downdraft airflow divergence in the near-surface layer is enhanced by convection by forced uplift so that the inflowing warm and humid airflow rises more strongly.

In general, the weather situation configuration of the day is conducive to the occurrence of strong convective weather, and it is in line with the high-altitude trough type (hot and low-pressure convergence line type) of the Guizhou hail model. From the perspective of the allocation of three environmental yields, the winds occur. The probability is great.

In general, the weather situation configuration of the day is conducive to the occurrence of strong convective weather, and it is in line with the high-altitude trough type (hot and low-pressure convergence line type) of the Guizhou hail model. From the perspective of the allocation of three environmental yields, the winds occur. The probability is great.

From the three related indicators, the small CAPE value is likely to cause insufficient consideration of convection intensity, so the impact of the process on the potential forecasting stage is underestimated. The main weather characteristics of this typical strong convective weather are strong dry air in the middle and upper levels, and strong vertical wind shear caused by the superposition of dry and cold air and low-level warm and humid air. It can be said that strong dry air is an important factor affecting the storm in strength.

\section{Dry Cold Air Intrusion and Characteristics}

The foregoing sounding from Guiyang site and various environmental parameters reveal that strong dry and cold air is an important factor in the storm intensity of this strong convective weather. The satellite cloud map will be used below, 
and the strong dry air will be tracked and analyzed in combination with the physical quantity field.

\subsection{Characteristics of Dry and Cold Air Revealed by Water Vapor Images}

The water vapor cloud map can be used to monitor convective severe weather such as heavy rain and thunderstorms in a relatively straightforward manner. Due to the channel characteristics of the water vapor cloud image, the low-level clouds do not appear on the water vapor image. Therefore, the water vapor image can effectively reveal the large-scale flow pattern in the upper middle part of the troposphere. The most important features on the water vapor image are the dry zone, the wet zone and the boundary between them. Dry intrusion is dry cold air that sinks to the lower layer near the top of the troposphere. Dry intrusion has the development of using heavy rain. When dry intrusion is found, it can be used as one of the basis for the development of heavy rain (Rezaei \& Motamedzadegan, 2015; Zhang et al., 2012; Chakraborty \& Maitra, 2012).

The dark area development on the water vapor cloud map corresponds to the middle and upper level dry and cold air entrapment process, and the sinking motion and vertical ascending motion in the cloud body are strengthened; the white light area strengthens corresponding to the development of mesoscale cloud clusters, and the convection stretch height is high. In this process, there is a sharp contrast between the gray image of the water vapor image and the boundary of the white bright cloud. Although the darkness does not reach the standard of dry intrusion, the dark area of less than $-57.5^{\circ} \mathrm{C}$ on the water vapor image is selected for tracking (Figure 5). The high-level dry and cold air intrusion process is still visible: after the evening of April 5, 2017, the water vapor image dark area (western Yunnan) upstream of Guizhou has developed eastward, and the rear side of the bright area developed on the 5th of the 5th Dark areas also appeared, showing a distinct band shape. The dark area at this time was the strongest during the process, and the obvious " $\mathrm{V}$ " type dark area was visible on the south side of the MCS. The " $\mathrm{V}$ " type dark area is slowly developing eastward with the MCS. By about $00 \mathrm{pm}$ on the 6th, the dark area extends to the sky above Guizhou, and the area is reduced. The white bright cloud corresponding to the MCS also tends to weaken.

\subsection{The Dynamic Effect of Dry Cold Air}

The intruded dry and cold air is generally from the upper level, with a relative humidity of $<30 \%$ as a dry zone at $300 \mathrm{hPa}$. At 20 o'clock on April 5th, it can be seen corresponding to the dry and cold air developed on the water vapor image to the west (Figure 6 blue arrow). The $300 \mathrm{hPa}$ wind speed zone, but not reaching the large-scale jet stream level, can be regarded as the water vapor dry zone. The dry and cold air during this process corresponds to a large vortex zone. At the MCS birthplace in the northwestern part of Guizhou Province in the front end of the dry and cold air delivery, a high vortex center of 6PVU appears, 


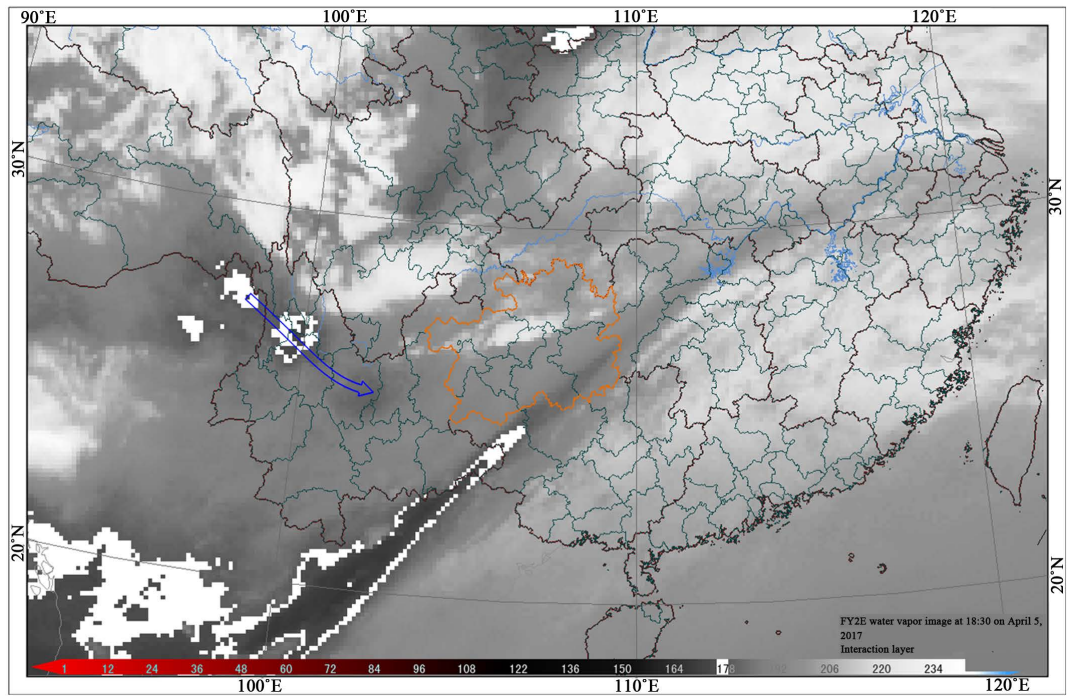

(a)

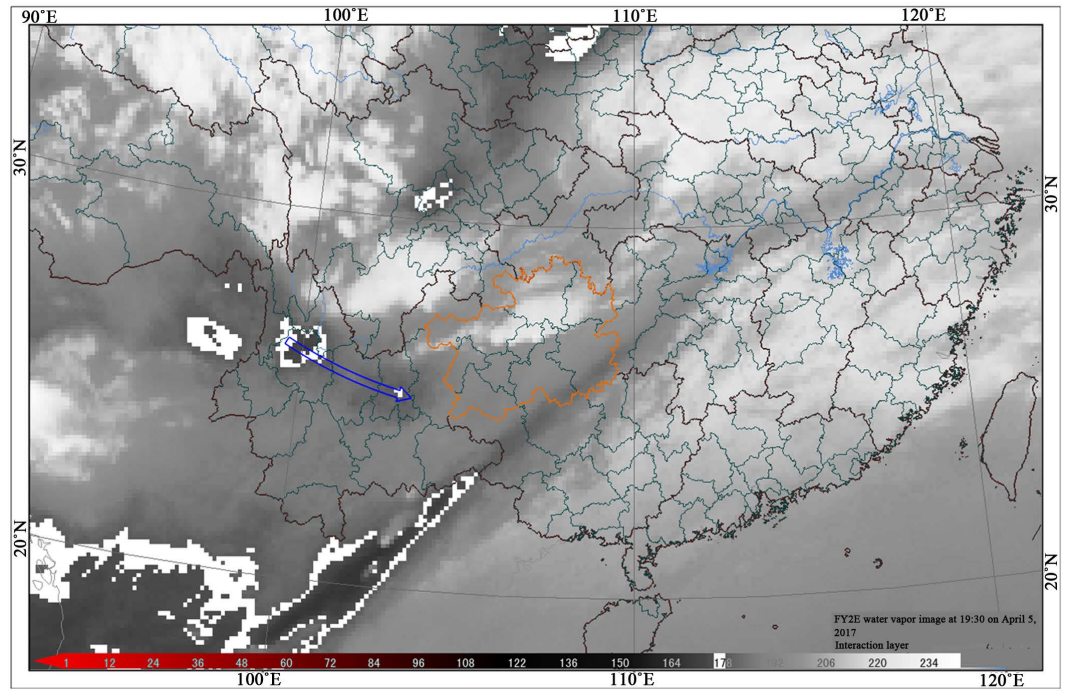

(b)

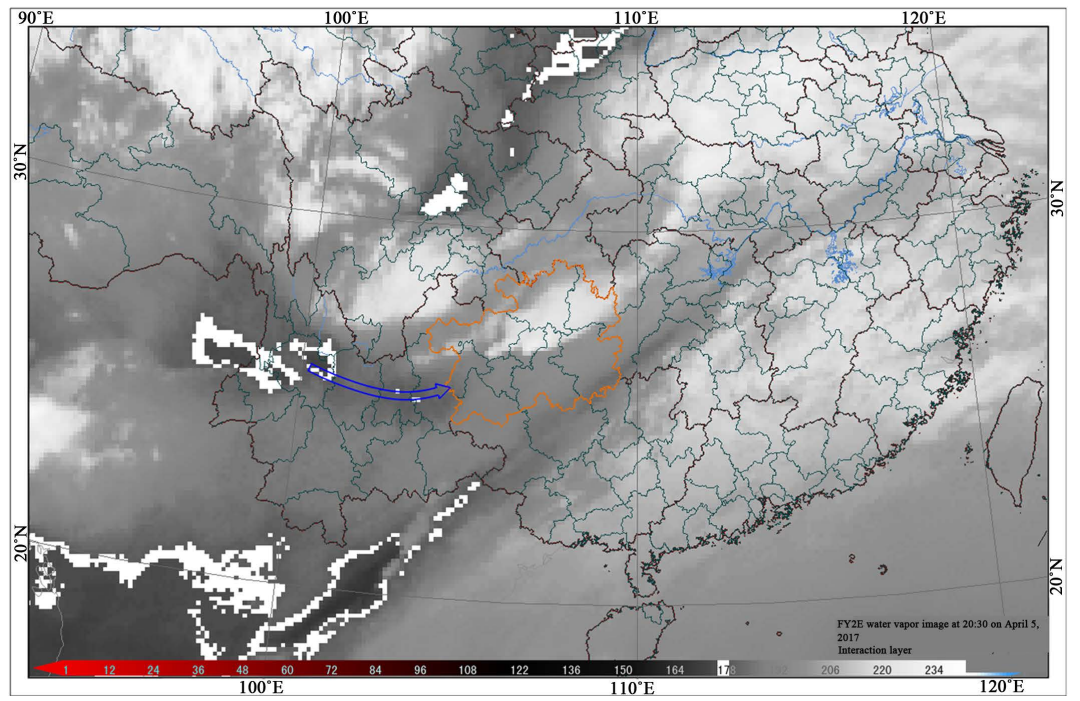

(c) 


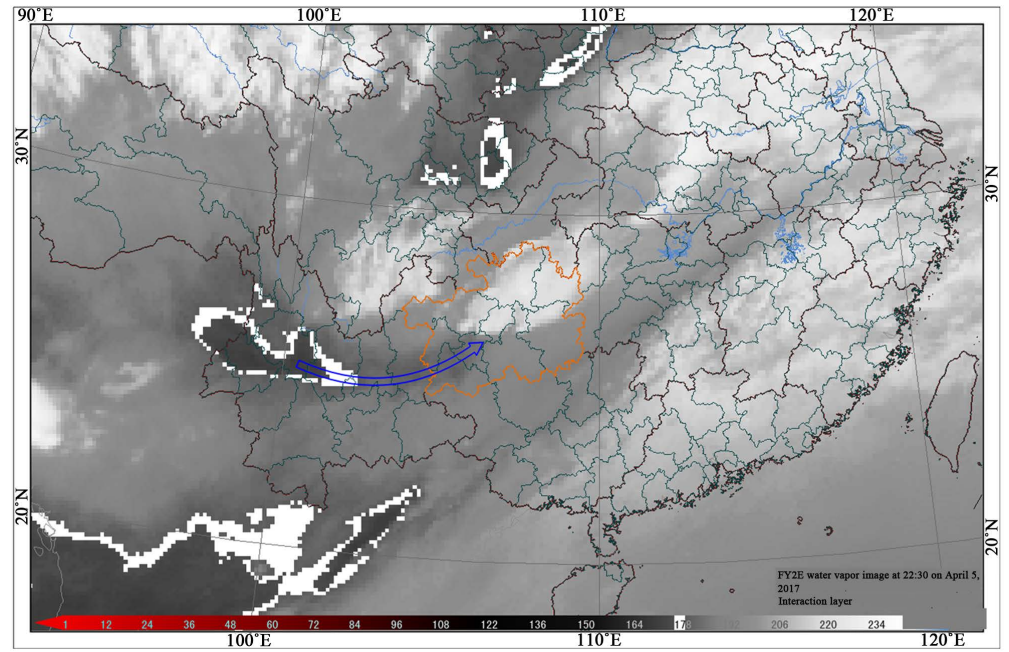

(d)

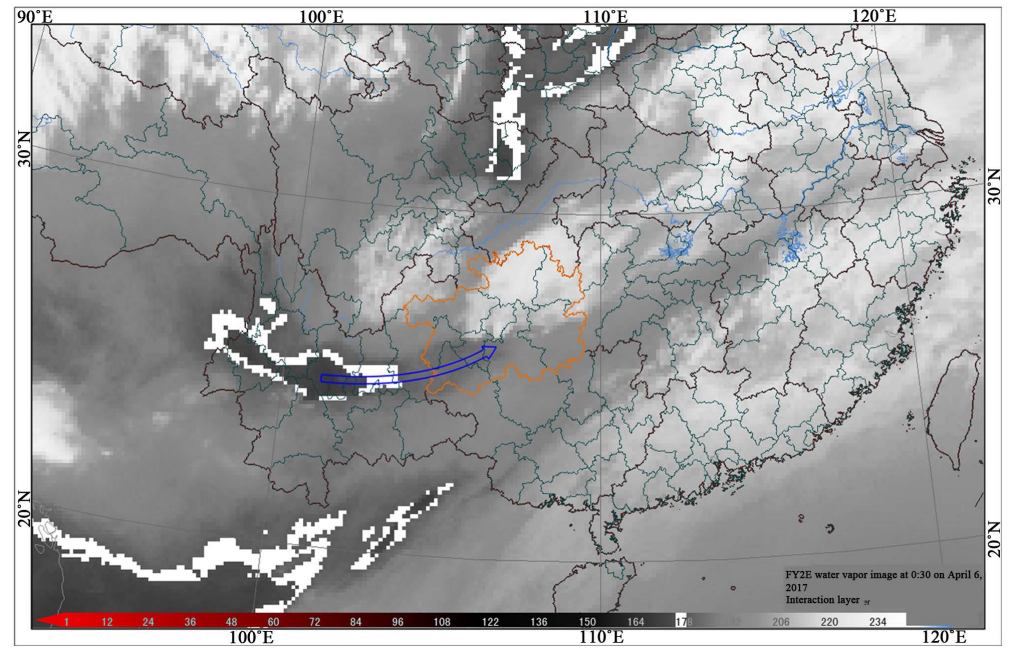

(e)

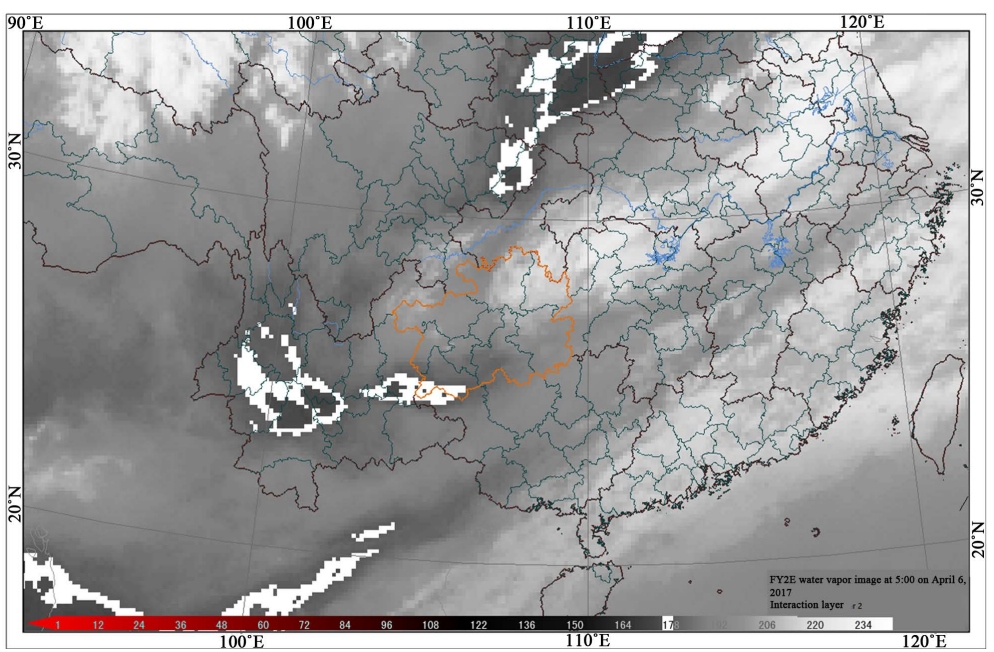

(f)

Figure 5. Water vapor cloud image at (a) 18:30; (b) 19:30; (c) 20:30; (d) 22:30 on April 5, 2017, and (e) 00:30; (f) 05:30 on April 5, 2017 (within the white line for the gray area > $\left.57.5^{\circ} \mathrm{C}\right)$. 


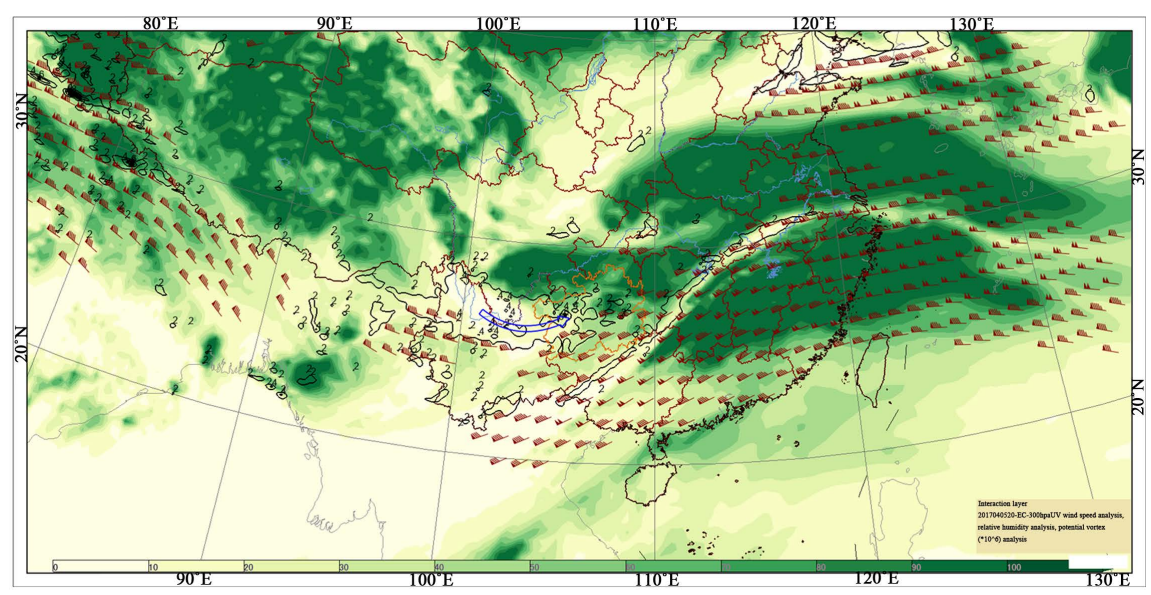

Figure 6. Weather situation on $300 \mathrm{hPa}$ level, at 20:00, April 5, 2017. (shadow: relative humidity, wind bar: wind $>16 \mathrm{~m} / \mathrm{s}$, black solid line: vortex $>2{ }^{\star} 10^{-6}$ ).

which is the performance of the vortex to the west of dry and cold air. From the meridional vertical section of the vortex (figure omitted), the high vortex center appears near the $300 \mathrm{hPa}$ high altitude and $700 \mathrm{hPa}$ in the middle and low altitude on the shear line. The high-altitude center is the embodiment of the strong dry air, and the middle and low-altitude center is the strong development of the storm body near the ground convergence line, which leads to the sharp increase of the relative vorticity and the downward vacancy of the high-altitude vortex, which makes the interaction of the cyclone development of the storm body.

From the meridional vertical section of 20:26.6 $\mathrm{E}^{\circ}$ on April 5, 2017 (Figure 7), it can be seen that the updraft of the MCS white bright cloud over the central part of Guizhou Province is strong until the tropopause is near $200 \mathrm{hPa}$. At 700 $\mathrm{hPa}$, the strongest intensity value is close to $16 \mathrm{~Pa} / \mathrm{s} * 10$. The dark area on the water vapor cloud map combined with the $500 \mathrm{hPa}$ high-altitude wind, found that the dry cold air source is mainly northerly winds below $500 \mathrm{hPa}$, and the dry cold air invades Guizhou from the west road with northerly wind. From the sinking speed, the strongest around $700 \mathrm{hPa}$ on the west side of the convergence line and the lower sinking speed on the east side reflect the vertical circulation of the MCS storm body and the invasion of dry and cold air, which strengthens the sinking on the west side of the convergence line. It also forms positive feedback on the strengthening of the middle and upper levels of dry and cold air. The dry cold air intrusion also strengthens the mid-layer span, allowing the vertical updraft and sinking airflow in the storm near the surface of the formation to be maintained and developed.

\subsection{Contribution of Dry Cold Air to Stability}

In this strong convective weather, near the $850 \mathrm{hPa}$ in the near-surface layer, due to the development of thermal low pressure, there is a distinct Ose high-energy tongue, the front end is the ground convergence line, and it is also the water vapor convergence area. The $\theta$ se high-energy tongue is also the embodiment of the strong warm and humid air flow. The 20:30 dry and cold air intrusion path on 


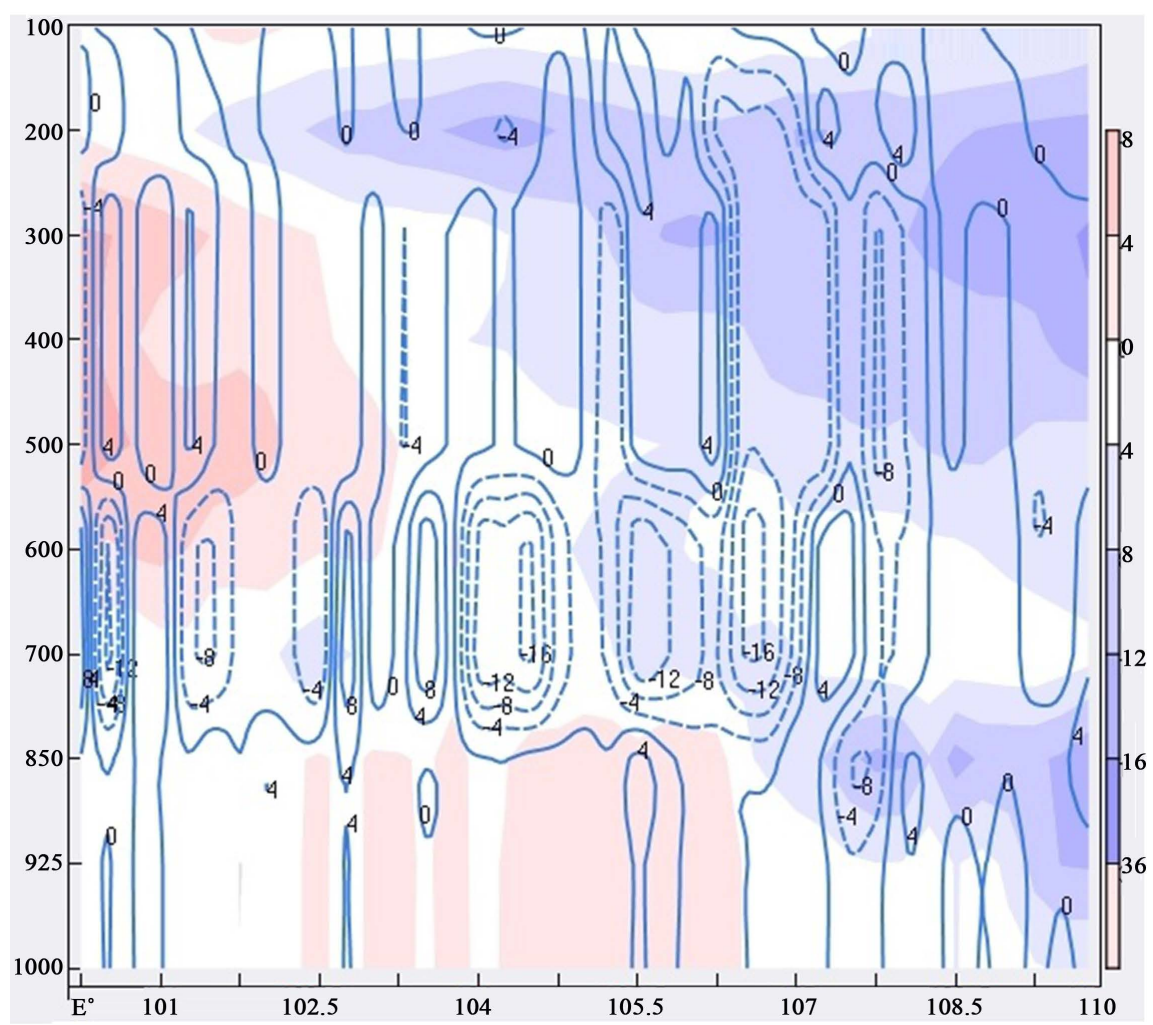

Figure 7. Vertical section of vertical speed (contour, $\mathrm{Pa} / \mathrm{s} * 10$ ) and $\mathrm{v}$ wind (mapping, $\mathrm{m} / \mathrm{s}$ ) along $26.6^{\circ} \mathrm{E}$ at 20:00, April 5, 2017 (note: the black line location near to Guiyang).

the water vapor image is superimposed with the low-level warm and humid airflow, which makes the instability of the central part of Guizhou significantly increase. From the cross-section of the temperature advection (figure omitted), there is a significant cold advection perpendicular to the shear line near $700 \mathrm{hPa}$, which is the strongest in Guiyang, and is the specific performance of dry and cold air from the upper level to the middle level. When the convective cloud develops into the middle layer of the troposphere, dry and cold air invades the warm and humid air mass, which makes the unstable energy in the storm increase and develops strongly.

\subsection{Characteristics of Dry Cold Air Intrusion on Radar Echo}

Before the storm arrived in Guiyang, from the basic reflectivity of the elevation angle of the Guiyang radar station at around 18:00 on April 5, 2017, the characteristics of the multi-cell storm were obvious, and there was a characteristic identification of the middle cyclone. V-shaped notches and hook-shaped echoes are the radar identification features of large hail. At 20:27, the echo moved to the northern part of Guiyang City. The echo intensity of the center reached $60-70$ $\mathrm{dBz}$, the top of the echo was about 16 kilometers, and the height of the strong echo center was about 7.5 kilometers. In the vertical direction, the overhanging form and the bounded weak echo region indicate the tilting and strong rotation of the storm cloud, and the warm and humid air mass is lifted to the upper level 
by the inclined airflow (Figure 8), which causes the warm and humid air mass to be invaded with the previously analyzed strong dry cold air. Forced uplift is consistent.

When three multi-monomers affect Guiyang, it is the moment of integration into a line storm near the width of the line. From the basic reflectivity factor and liquid water content, the storm is in a strong stage. At this time, the ground shear line, energy, and low-level water vapor are all in favorable conditions, and the dry and cold air intrusion is most obvious. After a strong ascending motion near the width of the line and the sinking motion of the dry and cold air, the

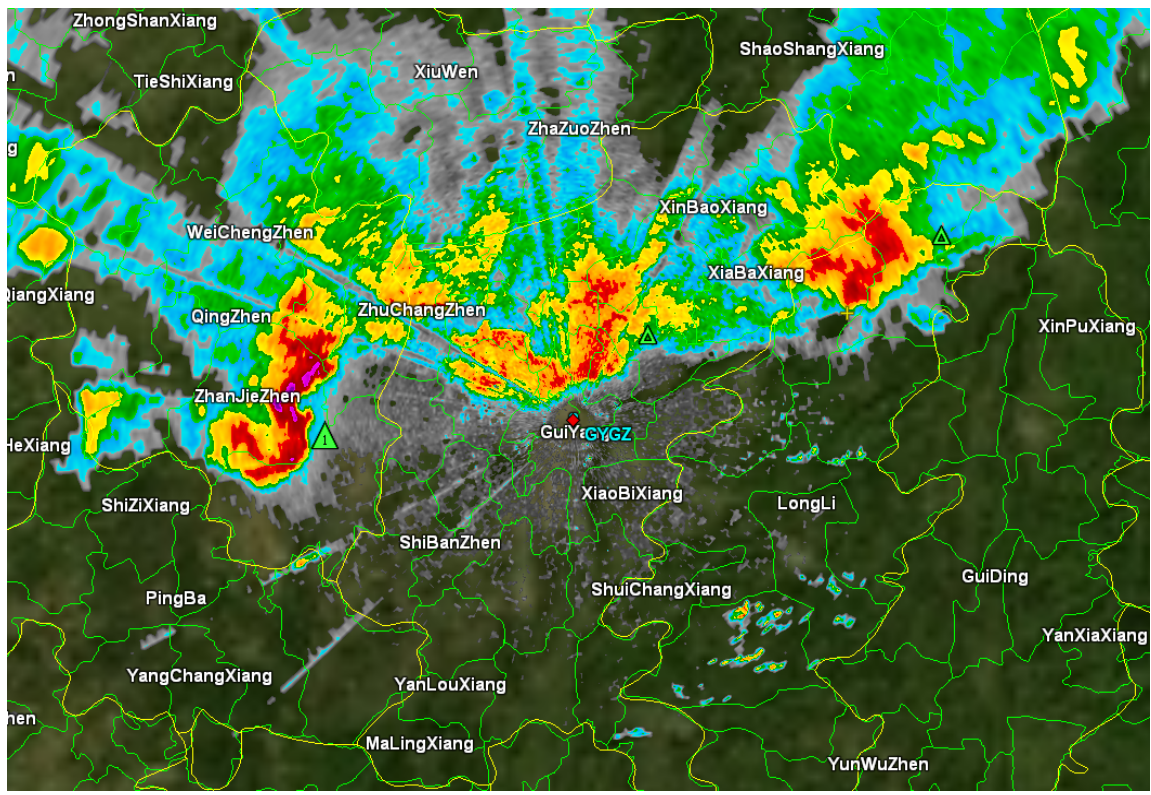

(a)

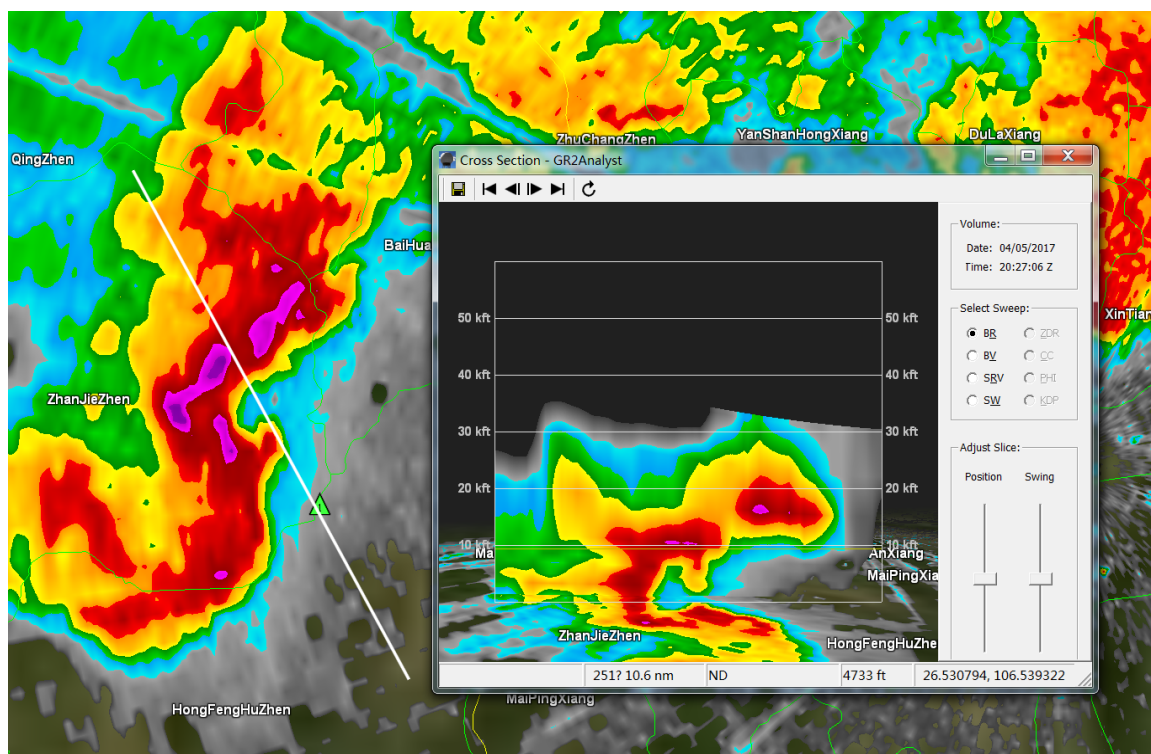

(b)

Figure 8. (a) Base reflectivity with $1.6^{\circ}$ elevation angleat 20:20; (b) Cross-section of reflectivity over Xindian town at 20:27 of Guiyang radar, April 5, 2017. 
storm energy is released. At this time, the ground shear line gradually becomes southward, and the dry and cold air inflow increases but the intensity weakens. The echo shows the structure of the storm body. It tends to be loose, and the storm body enters the decay phase.

\section{Conclusion}

On April 5, the circulation situation and environmental conditions are conducive to the occurrence of strong convective weather. It can be determined that the types of strong convective weather that may occur include hail and strong winds, which are typical strong convective weather. However, the potential prediction stage is insufficient to estimate the storm intensity due to the small CAPE value. Guiyang sounding shows that the main weather characteristics of this process are the strong dry air in the middle and upper levels, and the strong vertical wind shear caused by the superposition of dry cold air and low-level warm and humid air.

Dry cold air invades Guizhou from the west road with northerly wind, transports vortices into the MCS, and high vortex centers appear at $700 \mathrm{hPa}$ in the middle and low altitudes, which reflects the strong development of the storm body, resulting in a sharp increase in relative vorticity and high vacancies. The vortex is transported downwards, causing the interaction of the cyclonicity of the storm body. The strong sinking airflow on the west side of the convergence line forms a positive feedback for the reinforcement of the middle and upper layers of dry and cold air; the dry and cold air intrusion also strengthens the middle layer, making the vertical updraft in the storm body near the convergence line and the lower. The sinking airflow is maintained and developed.

The dry cold air intrusion path is superimposed with the low-level warm and humid air flow, which makes the instability of the central part of Guizhou increase obviously; the intrusion into the middle layer of dry cold air invades the warm and humid air mass, which makes the unstable energy in the storm increase and develops strongly.

\section{Acknowledgements}

This study was jointly funded by China's Core Development Business Special "Development grid forecast integration and correction key technology" (YBGJXM (2017)03-10) and China Guizhou Provincial Meteorological Service Center's Mountain Flood Geological Disaster Prevention and Control Meteorological Support Project 2018 Construction Project "Integrated Traffic Safety Operation Guarantee Meteorological Service Business-Shanghai-Kunming High-speed Railway Meteorological Service Business System".

\section{Conflicts of Interest}

The authors declare no conflicts of interest regarding the publication of this paper. 


\section{References}

Browing, K. A., \& Golding, B. W. (1995). Mesoseale Aspects of a Dry Intrusion within a Vigorous Cyclone. Quarterly Journal of the Royal Meteorological Society, 121, 463-493.

Browning, K. A. (1997). The Dry Intrusion Perspective of Extra-Tropical Cyclone Development. Meteorological Applications, 4, 317-324. https://doi.org/10.1017/S1350482797000613

Chakraborty, S., \& Maitra, A. (2012). A Comparative Study of Cloud Liquid Water Content from Radiosonde Data at a Tropical Location. International Journal of Geosciences, 3, 44-49. https://doi.org/10.4236/ijg.2012.31006

Chen, J., Li, X., Yu, Y. et al. (2017). Analysis of a Large-Scale Elevated Thunderstorm and Hail Weather Process in Tongren, Guizhou. Journal of Arid Meteorology, 35, 649-656.

Chen, X., Hao, Y., Zhou, H. et al. (2007). Analysis of Convective Parameters of a Rare Hail Weather Process. Scientia Meteorologica Sinica, 27, 335-341.

Johns, R. H., \& Doswell, C. A. (1992). Severe Local Storms Forecasting. Weather Forecasting, 7, 588-612.

Lei, Y. (1986). Energy Weather (pp. 108-128). Beijing: Meteorological Press.

Leslie, R. (1998). Lemon on the Mesocyclone "Dryintrusion" and Tornadogenesis (pp. 752-755).

Li, D., Tang, R., Xiong, S. et al. (2011). Radar Characteristics and Immediate Prediction of Strong Hail and Short-Term Heavy Precipitation Weather. Meteorological Monthly, 37, 474-480.

Liu, Y., Shou, S., Jie, Y. et al. (2011). Diagnostic Analysis of the Influence of Thermal Inhomogeneous Field on a Hail Weather. Plateau Meteorology, 30, 226-234.

Qian, C., Zhang, J., Ying, D., \& Lin, J. (2007). Diagnostic Analysis of a Strong Convective Weather Process in Jiangxi Province in April 2003. Quarterly Journal of Applied Meteorology, 18, 460-467.

Rezaei, M., \& Motamedzadegan, A. (2015). The Effect of Plasticizers on Mechanical Properties and Water Vapor Permeability of Gelatin-Based Edible Films Containing Clay Nanoparticles. World Journal of Nano Science and Engineering, 5, 178-193. https://doi.org/10.4236/wjnse.2015.54019

Wan, X., Zhou, M., Zeng, L. et al. (2017). Quantitative Conceptual Model Study and Trial Application Analysis of Spring Heavy Hail Weather in Guizhou. Guizhou Meteorology, 41, 1-7.

Wang, X., Zhong, Q., \& Han, S. (2009). A Case Study of a Strong Convective Cloud Evolution and Super Monomer Structure in a Hail Weather. Plateau Meteorology, 28, 352-365.

Wu, J., \& Yu, X. (2009). Overview of Doppler Weather Radar Detection and Early Warning Technology in Strong Hail Weather. Journal of Arid Meteorology, 27, 197-206.

Xu, X., Wang, N., Liu, R., Guo, D., \& Hou, J. (2010). A Comparative Analysis of Two Strong Convective Hail Weather Processes in Shaanxi Province in 2006. Plateau Meteorology, 29, 447-460.

Yao, R., Tu, X., \& Du, K. (2015). Variation Characteristics of Meteorological Elements in the Boundary Layer of Two Hail Processes. Plateau Meteorology, 34, 1677-1689.

Yu, X., Wang, Y., Chen, M., \& Tan, X. (2005). A New Generation of Weather Radar and Strong Convective Weather Warning. Plateau Meteorology, 24, 456-464.

Yu, X., Yao, X., Xiong, T. et al. (2006). Principle and Business Application of Doppler Weather Radar (pp. 90-95). Beijing: Meteorological Publishing. 
Yu, Y., \& Yao, X. (2003). Research on Dry Intrusion and Its Application Progress. Acta Meteorologica Sinica, 66, 769-778.

Zhang, Y., Wang, X., \& Chen, Y. (2012). An Improved 6S Code for Atmospheric Correction Based on Water Vapor Content. Advances in Remote Sensing, 1, 14-18. https://doi.org/10.4236/ars.2012.11002

Zheng, Y., Li, Y., Cai, Q. et al. (2014). Analysis of Environmental Conditions and Supercell Evolution Characteristics of a Rare Strong Hail Process in Hainan. Heavy Rain Disaster, 33, 163-170.

Zhou, Y., Zhou, M., \& Yuan, Y (2012). Characteristics of Doppler Radar Products in the Mountainous Areas of Guizhou. Guizhou Meteorology, 36, 40-43. 